\title{
An Improved Current-Doubler Rectifier for the Marine Controlled Source Electromagnetic Transmitter
}

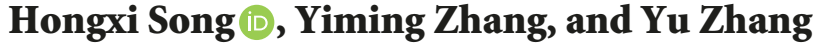 \\ Faculty of Information Technology, Beijing University of Technology, Beijing 100124, China \\ Correspondence should be addressed to Hongxi Song; shxbill@163.com
}

Received 20 August 2017; Revised 15 November 2017; Accepted 29 November 2017; Published 11 February 2018

Academic Editor: R. Aguilar-López

Copyright (C) 2018 Hongxi Song et al. This is an open access article distributed under the Creative Commons Attribution License, which permits unrestricted use, distribution, and reproduction in any medium, provided the original work is properly cited.

\begin{abstract}
High power marine controlled source electromagnetic transmitters have gained interest with applications in marine geological survey and mineral resources exploration. The direct current to direct current (DC-DC) converter that is typically used in marine transmitters has some issues, as the insulated-gate bipolar transistor (IGBT) tube cannot achieve zero-voltage switching (ZVS). In particular, lagging-leg switching cannot easily achieve ZVS. The conversion efficiency of the heat converter requires improvement. This paper proposes an improved current-doubler rectifier for the marine controlled source electromagnetic transmitter (ICDRMCSET). Resonant inductance is increased and a blocking capacitor is added to the converter (DC-DC) circuit, where the converter can achieve ZVS in a wide load range. This results in the effective decrease of the heating temperature and the improvement of transformation efficiency. Saber software simulation and a $20 \mathrm{KW}$ electromagnetic transmitter are used to verify the results, which show that the method is feasible and effective.
\end{abstract}

\section{Introduction}

There has been a recent increase of marine mineral exploration investment, which is expected to gradually move from offshore research to deep-sea exploration. There is a need to develop an electromagnetic exploration system that can control the deep-sea mineral resources with independent intellectual property rights. There is some current research that provides technical support for the exploration and the development of deep-sea mineral resources [1,2]. The marine controlled source electromagnetic method that is used in detecting submarine oil and gas reservoirs has been improved over the years. This method can identify high resistivity reservoirs, which will improve the drilling success rate. Current marine geophysical exploration technology services such as Electromagnetic Geoservices (EMGS) and WesternGeco or international oil companies such as Exxon Mobile, Statoil, or Shell have conducted nearly 1000 marine electromagnetic exploration projects [3]. The electromagnetic sounding system uses electromagnetic sounding transmitters towed by tugs to excite the electromagnetic waves at the bottom of the sea. A multicomponent electromagnetic receiver is placed at the bottom of the ocean to measure the electromagnetic field values. The distribution characteristics of underground electricity are detected by calculating the apparent resistivity and phase, or by directly using the observed electric field and magnetic field. This allows the distribution pattern of marine bottom structure and mineral resources to be observed $[4,5]$. Strong electromagnetic fields are formed at the bottom of the ocean using emission electrodes to emit high currents. The signal acquisition station then reclaims and analyzes these reflected electromagnetic signals so that the mineral resources, textures, and landforms of the seabed can be identified $[6,7]$.

Current marine electromagnetic detecting transmitters have many problems, including large volume, heavy mass, low efficiency, and poor transmitting waveforms, and they do not meet the current needs of actual exploration in the oil industry. The controlled source circuit is the core component of the marine electromagnetic sounding transmitter, which directly affects the performance and efficiency of the whole device $[8,9]$. The coaxial winding transformer has been used, where the leakage inductance of the transformer eliminates the voltage spike on the secondary coil. This expands the ZVS range of the load, and an equivalent model of the currentdoubler rectifier is obtained and analyzed [10]. A novel 


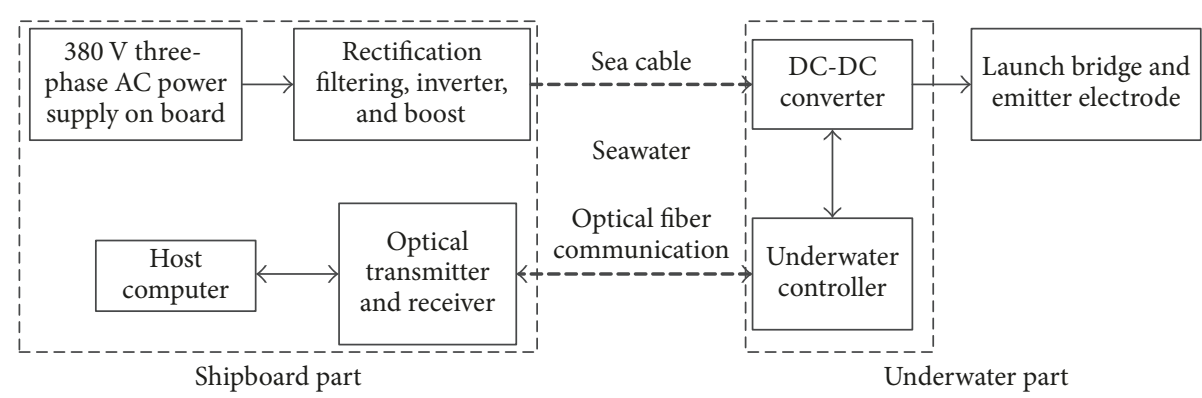

FIGURE 1: The marine controlled source electromagnetic transmitter overall structure.

welding machine has been proposed [11], which uses a diode instead of the rectifier. This can effectively reduce the output ripple current. In [12], soft switching is proposed to build a small signal model ocean electromagnetic transmitter, which improves transmitter efficiency and reduces overheating. A resonant inductor and two clamping diodes are added in the phase shift full-bridge direct current to direct current (DCDC) converter, greatly reducing the loss of insulated-gate bipolar transistor (IGBT) tube and high-frequency diode. A larger resonant inductor is used for the converter to achieve the ZVS at light load, but it easily causes the duty cycle to be lost; the analysis and experimental verification are given in this paper $[13,14]$. In [15], the zero-voltage and zero-current switching (ZVZCS) full-wave rectification DC-DC circuit is proposed; it improves the efficiency of the traditional marine controlled source electromagnetic transmitter (T-MCSET) and reduces the duty cycle loss and expands the adaptive range of the load.

As is seen in Figure 1, the marine transmitter is divided into a ship portion and an underwater portion. The ship portion contains a ship deck generator, a rectifier circuit, a personal computer (PC) monitoring unit, and an optical transceiver. The underwater portion contains the underwater tow, the DC-DC controlled source circuit, the launching bridge, the underwater controller, and the transmitting electrode [12].

The shipboard generators provide the initial electrical energy for the entire electromagnetic detection launching system. The deck rectifier filter circuit primarily enables the three-phase alternating current (AC) voltage generated by the shipboard generator to be converted into direct current (DC) voltage; the single-phase AC voltage is obtained by inverting the $\mathrm{DC}$ voltage; the transformer $T_{2}$ boosts the AC voltage, and this provides high-voltage single-phase AC power for the underwater pressure cabin, so that the losses produced by the transmission of the cable from the ship to the underwater transmitter are reduced. The monitoring unit of the upper deck establishes remote communication by the tow cables and the underwater launch system control units when the cabin pressure is initialized. This allows the underwater cabin pressure to be controlled and monitored. The module contains a global positioning system (GPS) module that can be used for the entire transmitter system.

The underwater shipboard tow is used in the mechanical connection between the ship and the pressure cabin to make the power and signal transmission be carried out simultaneously. The single-phase AC voltage is converted into DC voltage by the underwater portion rectifier filter circuit, so the controlled source DC voltage is then converted into a frequency adjustable square wave alternating current by the DC-DC controlled source circuit, and the electric energy is stimulated into the sea medium via a transmitting electrode. The control unit chips of the launching system implement the digital signal process (DSP) to gain control of the DC-DC controlled source circuit and the square wave alternating current frequency, as well as the monitoring of the transmitter temperature [16]. The use of optical fiber communication establishes the communication connection between the transmitter and the host computer. The DCDC controlled source circuit is an integral part of the ocean transmitter, where its performance and efficiency directly affect the performance of the entire transmitter. In the following study, resonant inductance is increased and the blocking capacitor is added to the converter (DC-DC) circuit. This converter easily achieves the ZVS, resulting in a reduced heating temperature and an improved conversion efficiency. So, the marine transmitter works stably for a long time and produces a more stable waveform.

\section{Marine Controlled Source Circuit}

2.1. Traditional Marine Controlled Source Circuit. The traditional high power marine transmitter cannot fully achieve soft switching; the IGBT tube cannot achieve zero-voltage switching (ZVS); the converter efficiency is low, and it can overheat. The traditional phase shift full-bridge converter topology is seen in Figure 2.

\subsection{Analysis of Hard Switching and Soft Switching Processes.} Figures 3(a) and 3(b) show, respectively, hard switching turn-on process 1 and turn-off process 1 , which belongs to fully hard switching; when the switch is turned on and turned off, the change of voltage and current is synchronous from the beginning to the end, resulting in mass energy consumption. Hard switching turn-on process 2 and turnoff process 2 are considered as semihard switching, where the voltage and the current changes do not begin simultaneously, resulting in less energy consumption (Figures 3(c) and 3(d)). The traditional transmitter switching working condition is considered semihard switching. Figures 3(e) and 3(f) depict 


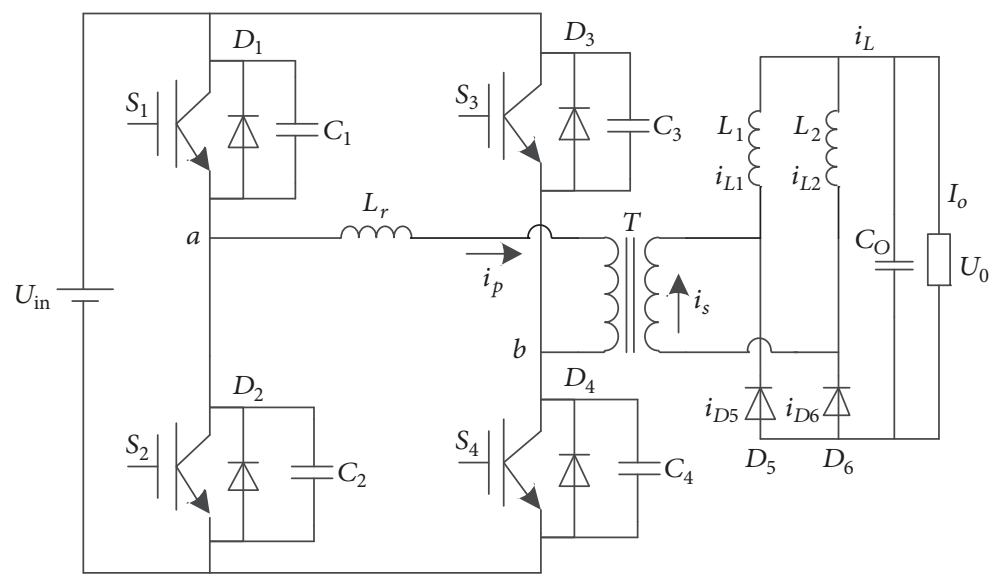

Figure 2: Traditional phase shift full-bridge converter topology.

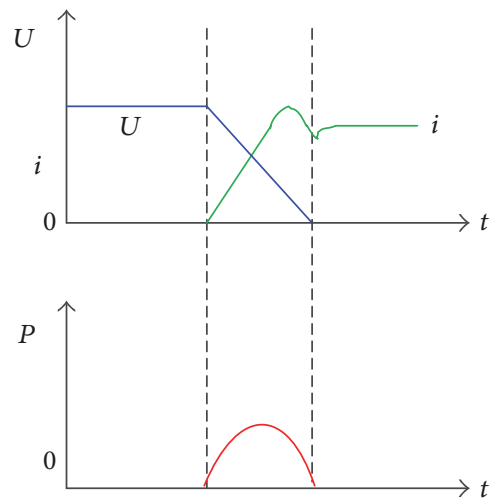

(a) Hard switching turn-on process 1

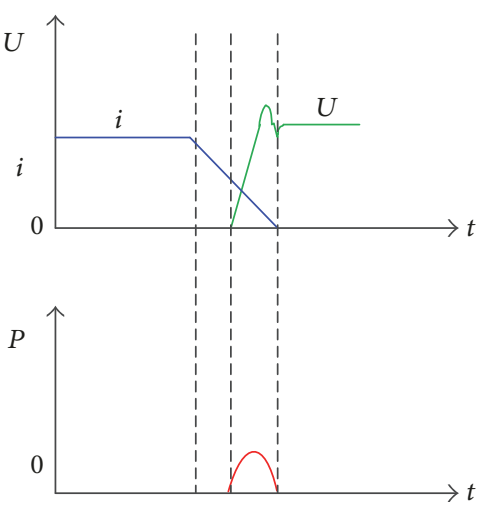

(d) Hard switching turn-off process 2

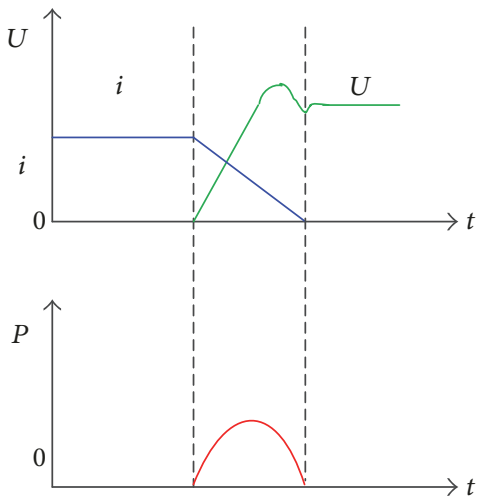

(b) Hard switching turn-off process 1

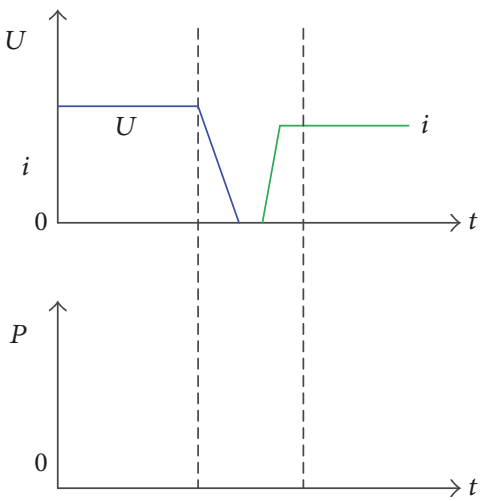

(e) Soft switching turn-on process

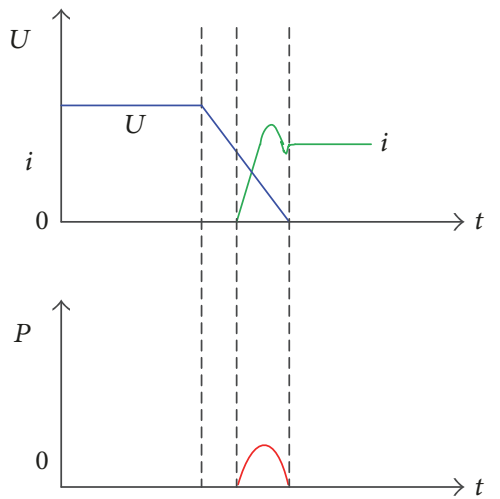

(c) Hard switching turn-on process 2

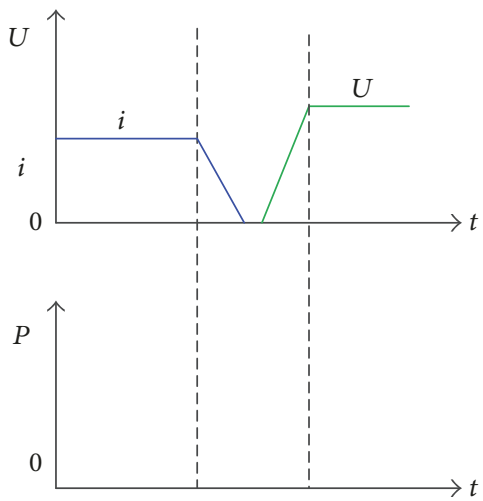

(f) Soft switching turn-off process

FIGURE 3: Switching turn-on and turn-off processes.

soft switching turn-on process 3 and turn-off process 3. Before the switch is turned on, the voltage drops to zero, and the current drops to zero again before the switch is turned off.

Hard switching has the following major problems $[17,18]$ :

(1) There are large switching losses. The switching of voltage and current waveform results in switching loss, which goes up rapidly with the increase of switching frequency.
(2) When the switch is turned off, there is a large voltage spike. The switching frequency becomes higher, the switch is turned off faster, the induction voltage increases much more, and device breakdown is more likely to happen.

(3) The current peak of the switch is large. The higher the frequency, the larger the current spike, resulting in overheating damage. 


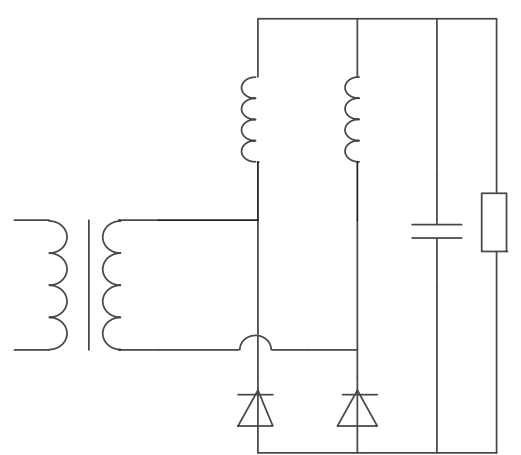

(a)

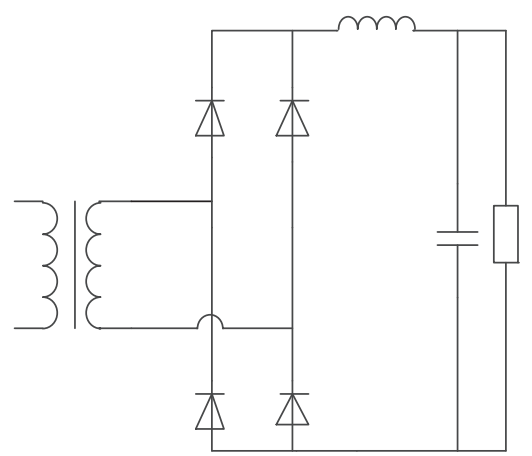

(b)

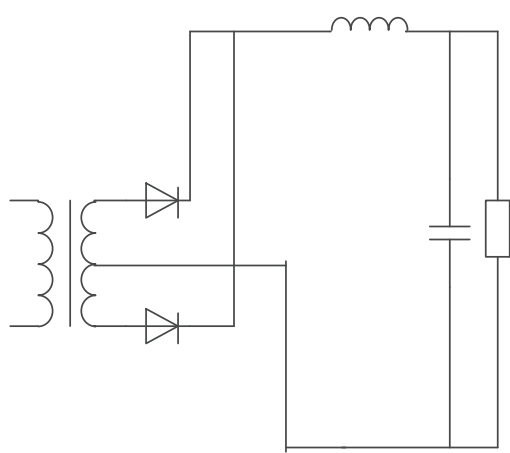

(c)

FIgURE 4: Several rectifier circuit diagrams.

(4) Electromagnetic interference is serious. The higher the frequency, the larger the $d i / d t$ and $d v / d t$ in the circuit, which leads to an increase in electromagnetic interference (EMI). This affects the normal operation of the rectifier and the surrounding electronic equipment.

These problems have limited the operating frequency of the switching device. Soft switching technology is an effective way to circumvent these problems. In this paper, an improved current-doubler rectifier is proposed for marine controlled electromagnetic transmitters. Resonant inductance is increased and a blocking capacitor is added to the converter (DC-DC) circuit in order to achieve the soft switching controlled source circuit. This converter can achieve ZVS in a wide load range while improving the efficiency of the converter. Overheating is reduced, and the control accuracy of the output voltage and current is enhanced. The controlled source circuit is then analyzed. There are 12 operating states within 1 cycle of the soft switching controlled source circuit $[19,20]$. A simulation and a $20 \mathrm{KW}$ transmitter are used to verify this method, which seems feasible and effective.

\subsection{Circuit Comparison. There are several rectifier circuits as shown in Figure 4 [21].}

Some common rectifier circuits are shown in Figure 4. The current-doubler rectifier circuit is shown in Figure 4(a). The full-wave rectifier circuit is shown in Figure 4(b). The full-bridge rectifier circuit is shown in Figure 4(c). The commonly used current-doubler rectifier circuit is compared with the full-wave rectifier circuit. The current-doubler rectifier circuit has the following advantages: the current effective value of transformer secondary winding is reduced, and the utilization ratio of the transformer is high; without center tap, the output current ripple is reduced to $1 / 2$ of the secondary winding current ripple of the transformer, and the frequency of the current ripple is doubled. Therefore, the filter inductance and capacitance needed for the output voltage and current can be smaller, so the current-doubler rectifier circuit is also more suitable for distributed power dissipation requirements in the improved current-doubler rectifier for the marine controlled source electromagnetic transmitter (ICDR-MCSET), and it also has a good heat dissipation function. The current-doubler rectifier circuit is compared with the full-bridge rectifier circuit; the number of diodes used in the current-doubler rectifier circuit is reduced to half. However, the current-doubler rectifier circuit uses more than one output filter inductor, and the structure is slightly complicated.

\section{The Improved Circuit Structure and Working State Analysis}

3.1. Improved Circuit Structure. As is shown in Figure 5, this section analyzes the 12 operating states of the phase shift full-bridge current-doubler rectifier. The analysis assumes the following conditions $[17,22]$ :

(1) All switching tubes, diodes, inductors, capacitors, and transformers are ideal components.

(2) $C_{1}=C_{2}=C_{12}, C_{3}=C_{4}=C_{34}$, and $L_{1}=L_{2}=L_{0}$.

(3) The output filter capacitor $C_{0}$ is large enough.

3.2. The Improved Circuit Working State Analysis. The main waveforms of the DC-DC converter are seen in Figure 6, which help us analyze the circuit structure. It is assumed that the controlled source circuit satisfies the following conditions $[10,19,20,23-25]$.

(1) Switching Mode $1, t_{0}<t<t_{1}$. According to the equivalent circuit model (Figure 7(a)), during $t_{0}<t<t_{1}, S_{1}$ and $S_{4}$ are turned on. The transformer primary current $i_{p}$ flows through $S_{1}$, the transformer primary winding, the blocking capacitors, $C_{b}$, and $S_{4}$. The diode $D_{6}$ is turned on, and the diode $D_{5}$ is turned off. $N$ is the transformer winding ratio, where at $t_{0}$ the currents of the filter inductances $L_{1}$ and $L_{2}$ are $i_{L 1}$ and $i_{L 2}$, respectively. $i_{L}$ is the sum of $i_{L 1}$ and $i_{L 2}$. The expressions of the load current $I_{0}$ and the primary current $i_{p}$ are as follows:

$$
\begin{aligned}
i_{p}(t) & =\frac{i_{L 1}(t)}{N}, \\
i_{L} & =i_{L 1}+i_{L 2}, \\
I_{0} & =i_{L} .
\end{aligned}
$$




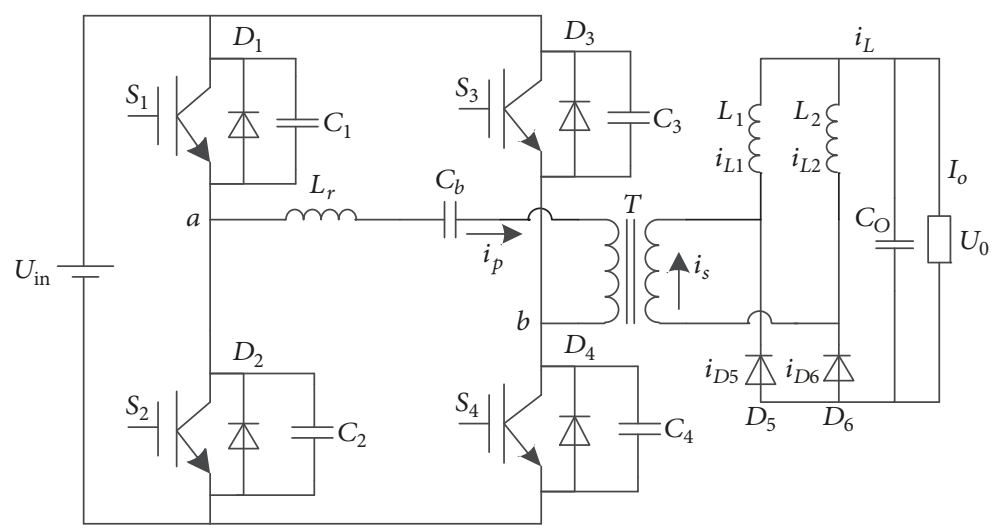

FIGURE 5: The improved phase shift full-bridge converter circuit diagram.

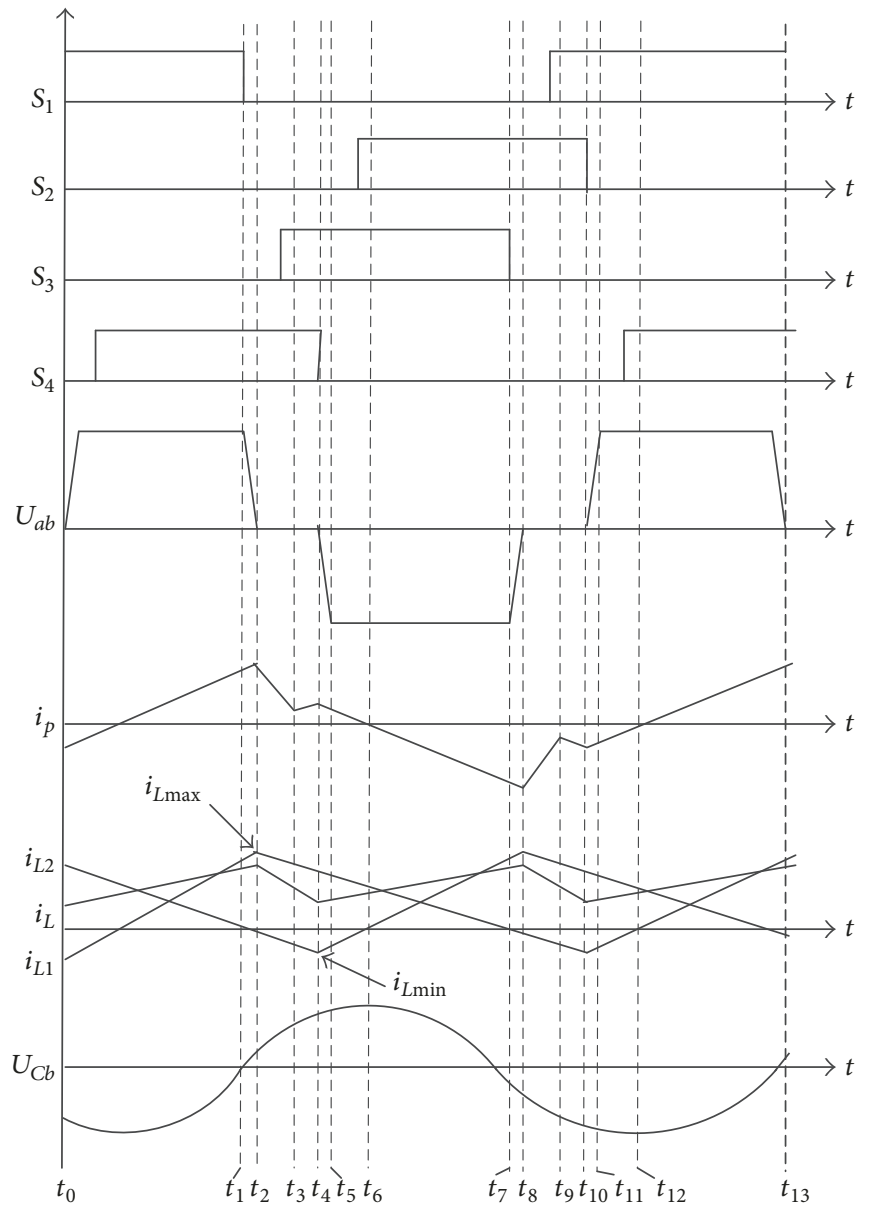

FIGURE 6: Main waveforms of the DC-DC phase shift full-bridge converter.

(2) Switching Mode 2, $t_{1}<t<t_{2}$. According to the equivalent circuit model (Figure $7(\mathrm{~b})$ ), at $t_{1}, S_{1}$ is turned on, and the current $i_{p}$ is charged to $C_{1}$ and is discharged to $C_{2}$. The rising rate of the voltage $U_{S 1}$ is limited by the capacitances $C_{1}$ and $C_{2}$, so $S_{1}$ is turned off under the ZVS mode. The $i_{p}$ current is charged to the $C_{b}$ blocking capacitors. During this period of time, $i_{p}=i_{L 1} / N$. The voltages of the capacitors $U_{C 1}$ and $U_{C 2}$ are represented as follows:

$$
\begin{aligned}
& U_{C 1}(t)=\frac{I_{P}\left(t_{1}\right)}{2 C_{13}}\left(t-t_{1}\right), \\
& U_{C 2}(t)=U_{\text {in }}-\frac{I_{P}\left(t_{1}\right)}{2 C_{12}}\left(t-t_{1}\right) .
\end{aligned}
$$

(3) Switching Mode 3, $t_{2}<t<t_{3}$. According to the equivalent circuit model (Figure $7(\mathrm{c})$ ), after $\mathrm{D}_{2}$ and $S_{2}$ are turned on, the 


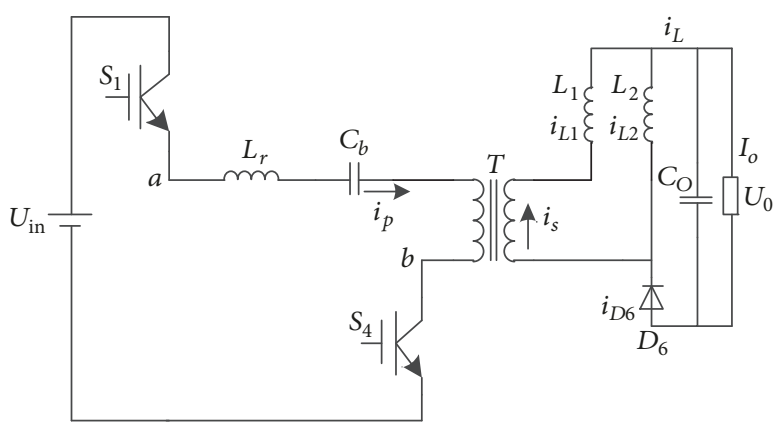

(a)

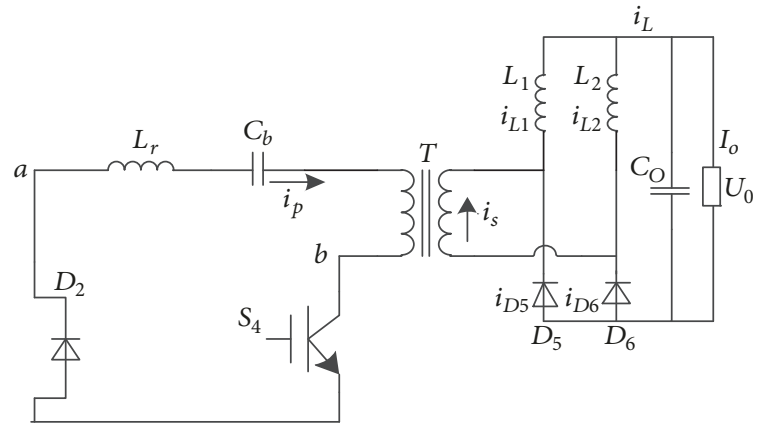

(c)

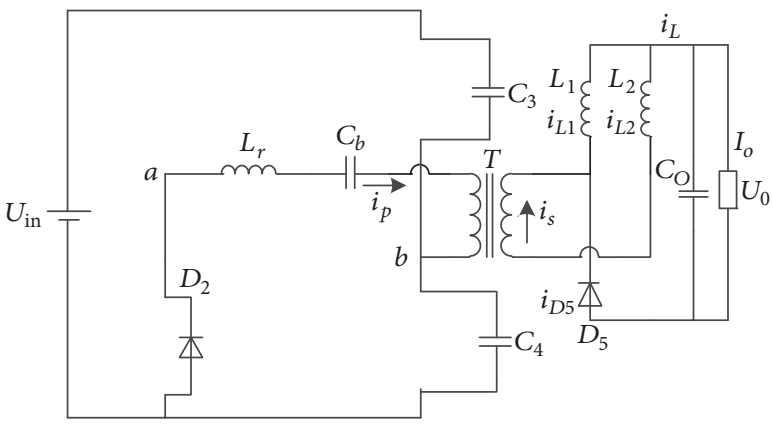

(e)

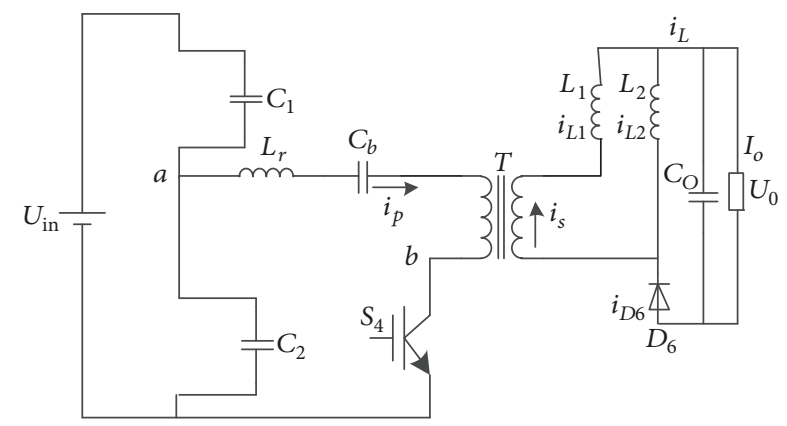

(b)

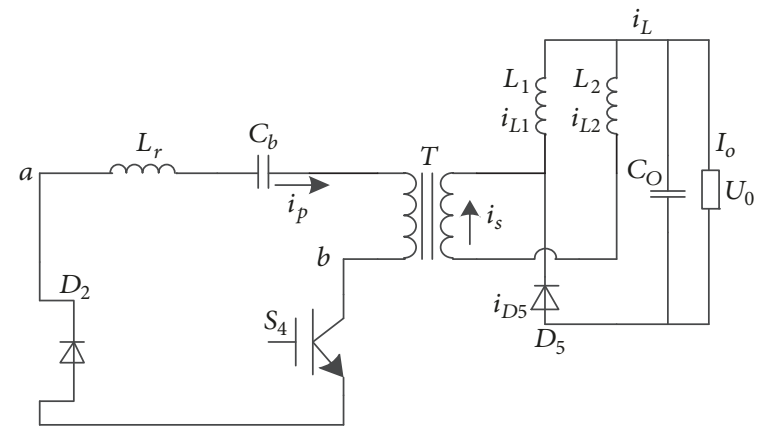

(d)

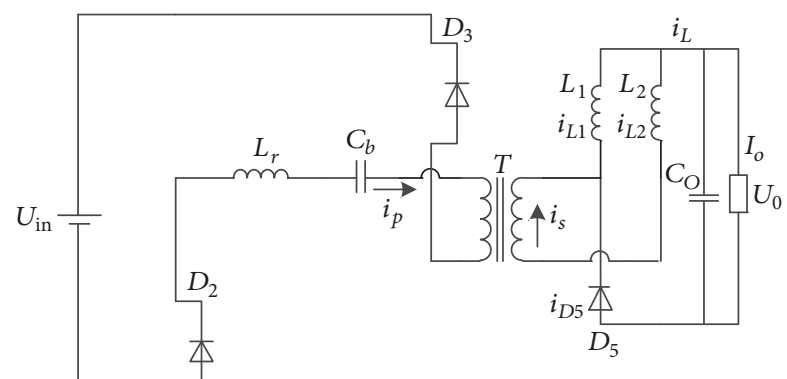

(f)

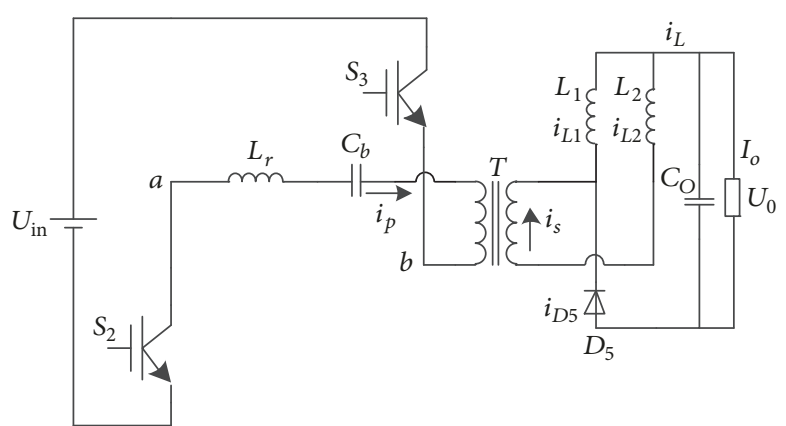

(g)

FIGURE 7: Equivalent circuit of the improved phase shift full-bridge converter.

dead time $\left(t_{d}\right)$ between the $S_{1}$ and $S_{2}$ drive signals should be larger than $t_{12}$. Although $S_{2}$ is turned on at this time, $S_{2}$ did not flow through the current, and the primary side current $i_{p}$ is circulated by the diode $D_{2}$. The secondary and primary voltages of the transformer are held at zero, when $D_{5}$ and $D_{6}$ are simultaneously turned off. This way, the voltage $U_{C b}$ is added to the leakage inductance $L_{r}$, which means that $C_{b}$ and $L_{r}$ are working in resonance. The voltage of the two filter inductors is $-U$, and the current is decreased linearly. The expressions of the blocking capacitor voltage $U_{C b}$ are

$$
\begin{aligned}
U_{C b}(t)= & \omega L_{r} I_{P}\left(t_{2}\right) \sin \omega\left(t-t_{2}\right) \\
& +U_{C b}\left(t_{2}\right) \cos \omega\left(t-t_{2}\right),
\end{aligned}
$$




$$
\omega=\frac{1}{\sqrt{L_{r} C_{b}}}
$$

(4) Switching Mode 4, $t_{3}<t<t_{4}$. According to the equivalent circuit model (Figure $7(\mathrm{~d})$ ), during this time, $D_{2}$ and $S_{4}$ continue to be turned on, as $U_{a b}=0, D_{6}$ is turned off, and $D_{5}$ is turned on. The two-voltage inductance filter is $-U_{o}$, and the current of the two filter inductors is continuously decreased linearly when $i_{o}=-i_{L 2}, i_{p}=-i_{L 2} / N$.

(5) Switching Mode 5, $t_{4}<t<t_{5}$. According to the equivalent circuit model (Figure 7(e)), at $t_{4}, S_{4}$ is turned off, and the current $i_{p}$ is charged to $C_{4}$ and is discharged to $C_{3}$. The rising rate of the voltage $U_{S 4}$ is limited by the capacitances $C_{3}$ and $C_{4}$, so $S_{4}$ is turned off under the ZVS mode. The current $i_{p}$ is charged to the blocking capacitors $C_{b}$ and the voltage $U_{C b}$ is raised. $i_{p}$ can be considered as a constant current source, where the voltages of the capacitors $C_{3}$ and $C_{4}$ are represented as

$$
\begin{aligned}
& U_{C 4}(t)=\frac{I_{P}\left(t_{4}\right)}{2 C_{34}}\left(t-t_{4}\right), \\
& U_{C 3}(t)=U_{\text {in }}-\frac{I_{P}\left(t_{4}\right)}{2 C_{34}}\left(t-t_{4}\right) .
\end{aligned}
$$

(6) Switching Mode 6, $t_{5}<t<t_{6}$. According to the equivalent circuit model (Figure 7(f)), when $D_{3}$ and $S_{3}$ are turned on, the dead time $\left(t_{d}\right)$ between the $S_{3}$ and the $S_{4}$ drive signals should be larger than $t_{45}$. Although $S_{3}$ is turned on at this time, it does not flow through the current. The primary side current $i_{p}$ is circulated by the diode $D_{3} . i_{p}$ is decreased linearly and the voltage $U_{C b}$ continues to rise.

(7) Switching Mode $7, t_{6}<t<t_{7}$. According to the equivalent circuit model (Figure $7(\mathrm{~g})$ ), $S_{2}$ and $S_{3}$ are turned on, $i_{L 1}$ is decreased, $i_{L 2}$ is increased, $i_{p}$ is increased in the negative direction, and the voltage $U_{C b}$ continues to decrease. At $t_{7}$, the converter begins the other half of the cycle $t_{7}<t<t_{13}$, where the working condition is similar to the previous half cycle $t_{1}<t<t_{7}$.

3.3. Soft Switching Implementation Conditions. Leading-leg switching is performed when the output filter inductance is at the maximum current $\left(t_{2}\right.$ and $\left.t_{8}\right)$ stored energy. The laggingleg switching is performed when the output filter inductance is at the minimum current $\left(t_{4}\right.$ and $\left.t_{10}\right)$. The main waveform of the phase shift full-bridge converter demonstrates that the average value of the output filter inductor current is $[10,11]$

$$
i_{L o}=\frac{i_{L \max }+i_{L \min }}{2} .
$$

The maximum and minimum values of the output filter inductor current are $i_{\max }$ and $i_{\min }$; when $t_{2}<t<t_{10}, i_{L 1}$ is dropped from $i_{\max }$ to $i_{\min }$. This is explained as follows:

$$
i_{L \max }-i_{L \min }=\frac{U_{O}}{L_{O}}\left(1-\frac{D_{e}}{2}\right) T_{0} .
$$

TABLE 1: Experimental circuit parameter design.

\begin{tabular}{lc}
\hline Parameters & Values \\
\hline Input voltage $\left(U_{\text {in }}\right)$ & $540 \mathrm{~V}$ \\
Output voltage $\left(U_{0}\right)$ & $100 \mathrm{~V}$ \\
Output current $\left(I_{o}\right)$ & $200 \mathrm{~A}$ \\
Switching frequency $\left(f_{o}\right)$ & $20 \mathrm{kHz}$ \\
The ratio of the primary and & \\
secondary sides of the & $5: 1$ \\
transformer $(N)$ & \\
Filter inductance $\left(L_{1}=L_{2}\right)$ & $47 \mathrm{uH}$ \\
Load $\left(R_{0}\right)$ & $0.5 \Omega$ \\
Filter capacitor $\left(C_{0}\right)$ & $1500 \mathrm{uF}$ \\
Absorption capacitance & $0.47 \mathrm{uF}$ \\
$\left(C_{1}=C_{2}=C_{3}=C_{4}\right)$ & $20 \mu \mathrm{F}$ \\
Blocking capacitor $\left(C_{b}\right)$ & $10 \mu \mathrm{H}$ \\
Resonant inductance $\left(L_{r}\right)$ &
\end{tabular}

$T_{0}$ is the switching cycle, and $D_{e}$ is the effective duty cycle of the converter.

$$
\begin{aligned}
& i_{L \max }=i_{L o}+\frac{U_{o}\left(2-D_{e}\right) T_{0}}{4 L_{0}}, \\
& i_{L \min }=i_{L o}-\frac{U_{o}\left(2-D_{e}\right) T_{0}}{4 L_{0}} .
\end{aligned}
$$

Formula (7) demonstrates that $i_{L \min }$ is negative, where the heavier the load is, the larger the value of $i_{L \max }$ is and the smaller the absolute value of $i_{L \min }$ is. This means that the zero-voltage switches are easier to be achieved in heavy load than in light load for the leading-leg switching. The lagging-leg switching achieves zero-voltage switching under the heavy load, which is more difficult than under light load. The leading-leg switching utilizes the zero-voltage switching more efficiently than the lagging-leg switching.

\section{Experimental Results}

To verify the theoretical analysis of the ICDR-MCSET, the blocking capacitor is added and the resonant inductance is amplified in the circuit, so that simulation and physical experiments can be performed.

4.1. Simulation Verification. The $20 \mathrm{KW}$ ICDR-MCSET is verified by the Saber simulation and the parameters are set as follows (Table 1).

The four IGBT tubes' drive wave is a phase shift fullbridge converter drive wave in the simulation (Figure 8). When the load current is $200 \mathrm{~A}$ (Figure 9), the lagging-leg switching voltages $U_{S 3}, U_{S 4}$, and $U_{a b}$ do not show a voltage rise or fall caused by the shock peak. This demonstrates that the converter is soft switching and the simulation is effective. In Figure 10, when the current-doubler circuit is adopted, the output current ripple is reduced to $1 / 2$ of the secondary winding current ripple of the transformer, and the frequency 

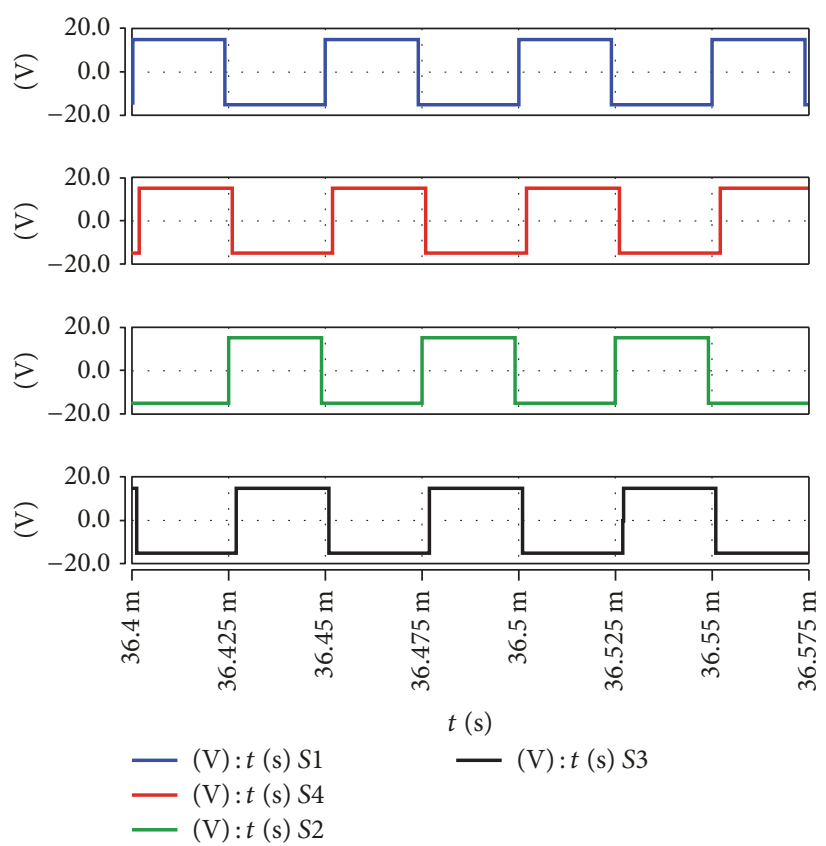

FIGURE 8: $S_{1}, S_{2}, S_{3}$, and $S_{4}$ IGBT tubes drive wave.
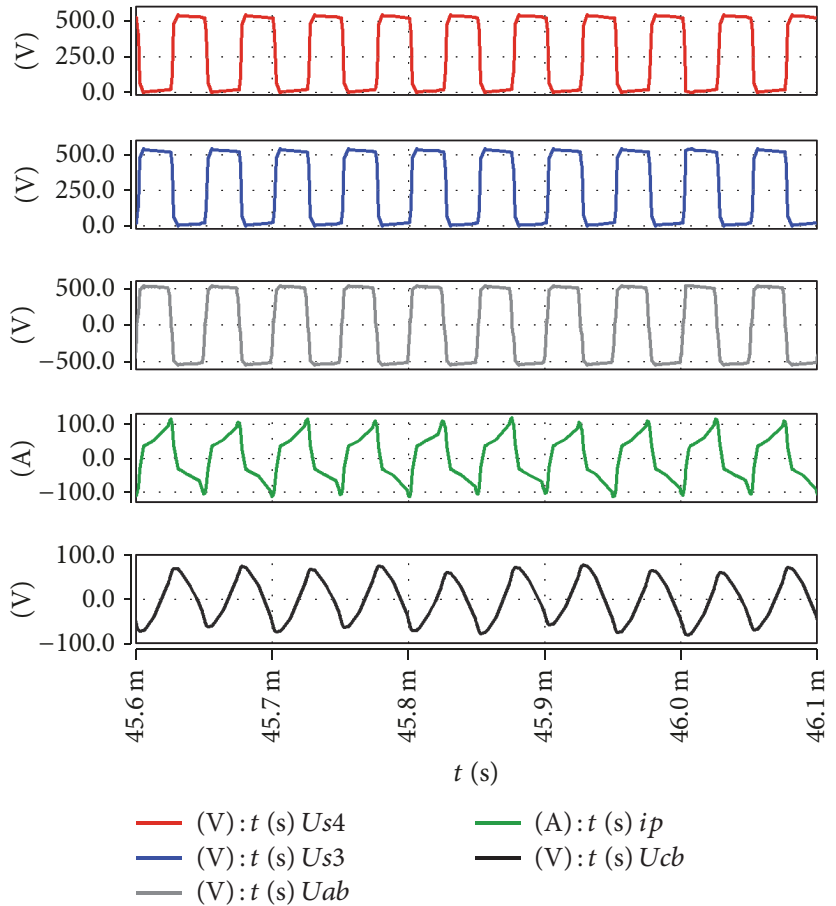

FIGURE 9: $U_{S 3}$ represents the voltage between the collector and the emitter of the 3-IGBT tube. $U_{S 4}$ represents the voltage between the collector and the emitter of the 4-IGBT tube. The primary winding voltage is $U_{a b}$, the primary winding current is $i_{p}$, and the blocking capacitor is $C_{b}$.

of the current ripple is doubled. The output voltage and the current load ripple are small with high stability (Figure 11).

4.2. Physical Verification. The $20 \mathrm{KW}$ ICDR-MCSET is verified by physical verification; Figure 11 is the physical picture of the ICDR-MCSET. The whole circuit is installed in a $70 \mathrm{~cm}$ (diameter) $* 190 \mathrm{~cm}$ (length) hermetic pressure cabin, with two ends connected with a single AC power supply and emission dipole. The IGBT module consists of two parts: module A and module B (Figure 12).

The four IGBT tubes' drive wave is a phase shift full-bridge converter drive wave in physical experiments 


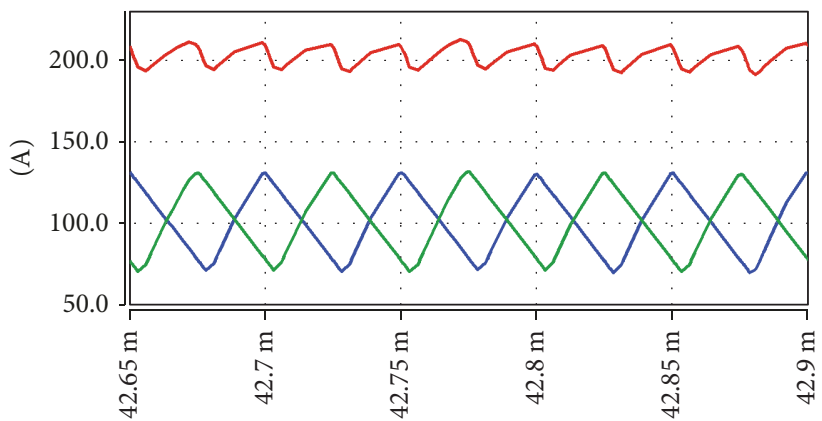

$t$ (s)

$$
\begin{aligned}
& -(\mathrm{A}): t(\mathrm{~s}) i L 1 \\
& -(\mathrm{A}): t(\mathrm{~s}) i L 2 \\
& -(\mathrm{A}): t(\mathrm{~s}) i L
\end{aligned}
$$

FIGURE 10: Two inductor currents are $i_{L 1}$ and $i_{L 2}$, which are superimposed on current $i_{L}$.
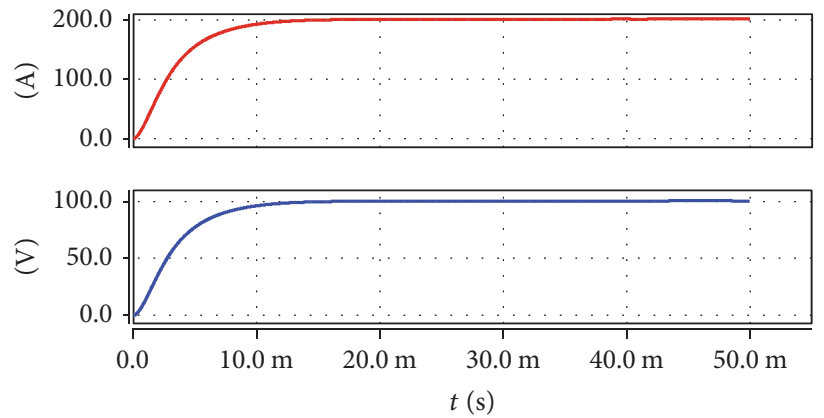

- (A) :t (s) Io

- (V):t $(\mathrm{s}) U_{0}$

FIGURE 11: Load current $=I_{0}$ and load voltage $=U_{0}$.

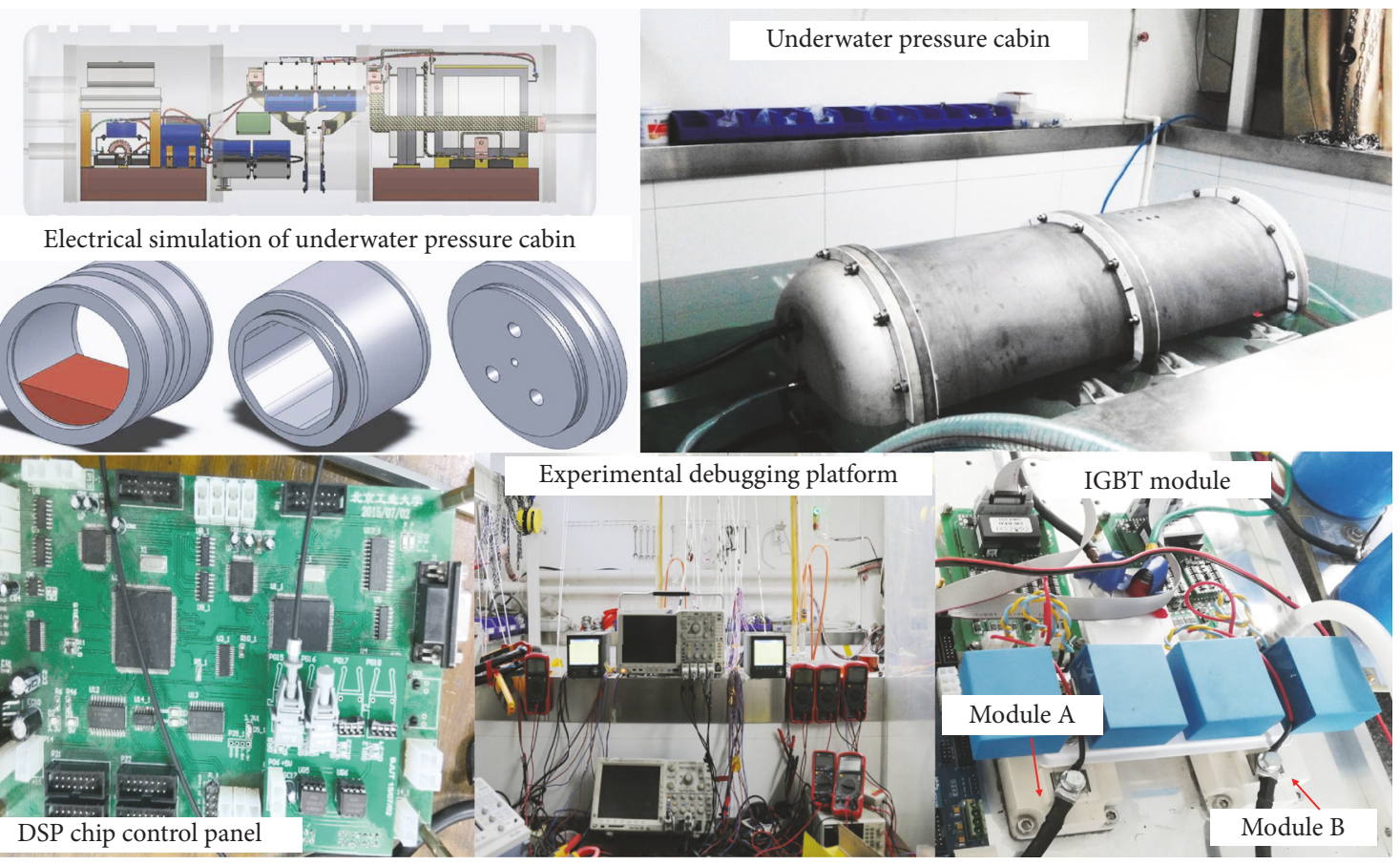

FIGURE 12: Marine controlled source transmitter circuit physical diagram. 


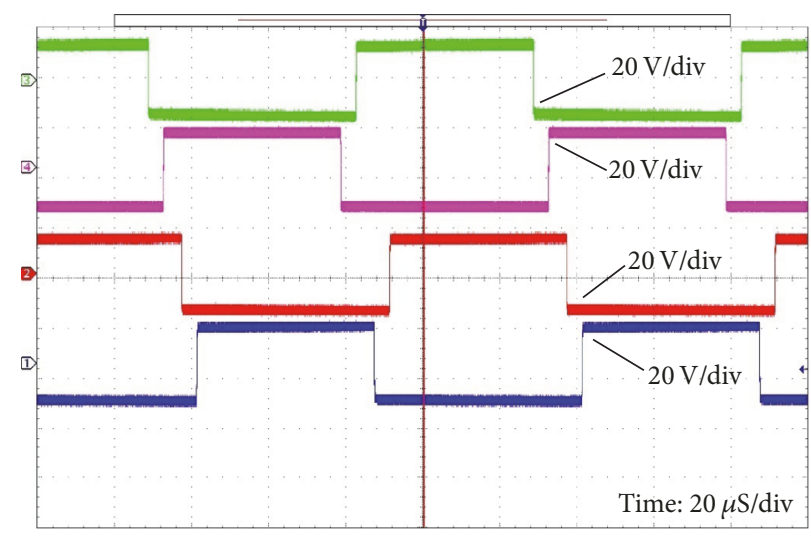

FIgURE 13: $S_{1}, S_{2}, S_{3}$, and $S_{4}$ IGBT tubes drive wave.

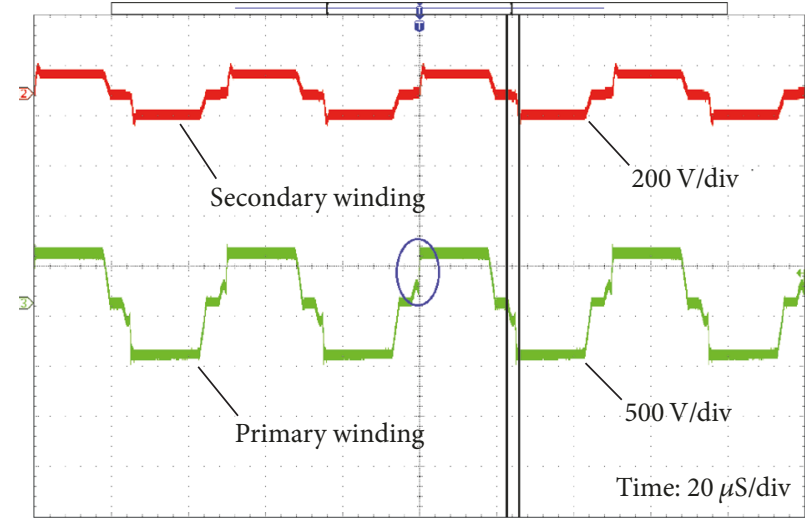

(a)

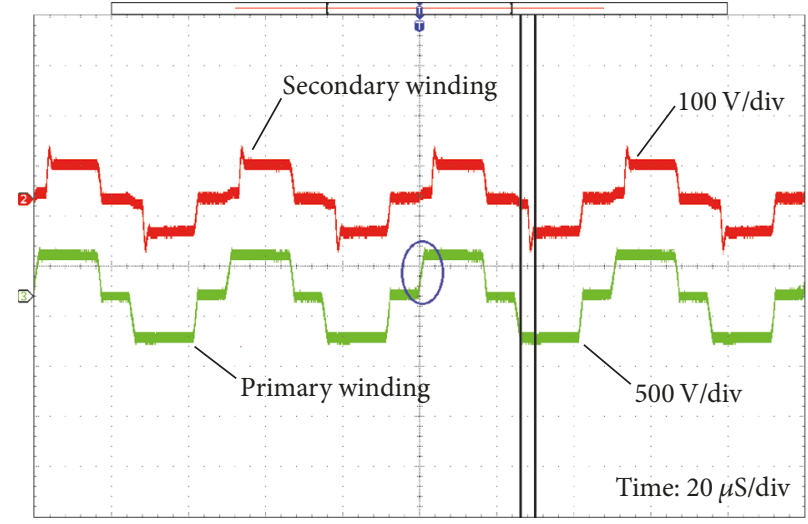

(b)

Figure 14: (a) The waveforms of the primary and the secondary voltage of the transformer are not in the ZVS mode. (b) The waveforms of the primary and the secondary voltage of the transformer are in the ZVS mode.

(Figure 13). According to Figure 14(a), the experiment shows that, in the blue ellipse, the primary winding of the transformer is not achieved in the ZVS mode from the T-MCSET, and it belongs to the semihard switching state. When the resonant inductance is increased and the blocking capacitor is added, the freewheeling current in the circuit is relatively large, its duration is long, and the corresponding diode is turned on and continues to flow current. The IGBT tube voltage begins clamping when the voltage is zero, so the primary voltage $U_{a b}$ does not exhibit a second buffer in the process of rising. As is shown in Figure 14(b), the primary winding of the transformer successfully achieves soft switching inside the blue ellipse from the ICDR-MCSET.

The lagging-leg switching $U_{S 4}$ is turned on (Figure 16) and does not appear during the rise of the second buffer. As is shown in Figures 14 and 16, the lagging-leg switching $U_{S 4}$ successfully achieves soft switching and so the primary winding voltage $U_{a b}$ of the transformer does not appear during the rise of the second buffer. As is shown in Figures 15 and 16, the two inductance currents are almost symmetrical. The two diode currents achieve natural commutation. The two inductance currents and the two diode currents are slightly different; these may be due to the fact that the internal parameters of the control circuit and the device are not completely consistent, which does not affect the experimental results.

The two-in-one IGBT modules (A and B) form a phase shift full-bridge converter. The temperature curve can be seen from Figure 17. When the transmitter continues operation for 5 hours, the temperatures of the transformer and IGBT modules are gradually increased with time. When the transmitter stays in operation for about 3.5 hours, the temperature of the T-MCSET transformer rises to $68^{\circ} \mathrm{C}$ as seen in Figure 17(a). However, the temperature of the ICDR-MCSET transformer rises to $52^{\circ} \mathrm{C}$ as seen in Figure $17(\mathrm{~b})$, and all temperatures have a stable trend. The temperature of the transformer is in a controllable range. Module $\mathrm{A}$ is shown as a red curve and module B is shown as a blue curve in Figures 17(c) and 17(d). When the transmitter operates for about 1 hour, the temperature of the T-MCSET IGBT modules rises to $42^{\circ} \mathrm{C}$ as seen in Figure 17(c). However, the temperature of the ICDRMCSET IGBT modules rises to $39^{\circ} \mathrm{C}$ as seen in Figure $17(\mathrm{~d})$, and all temperatures have a stable trend. The temperature of the IGBT modules is in a controllable range.

According to the above analysis from the ICDR-MCSET, the primary voltage $U_{a b}$ of the transformer does not exhibit a 


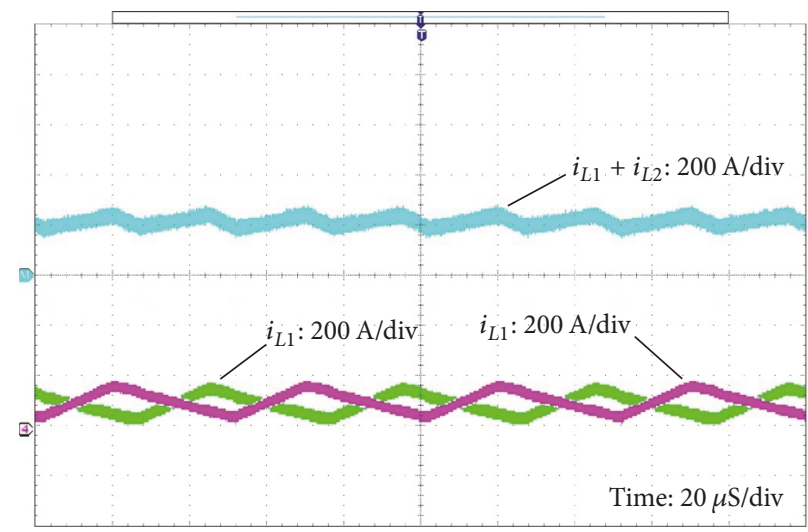

FIGURE 15: $i_{L 1}$ is the inductance $L_{1}$ current, $i_{L 2}$ is the inductance $L_{2}$ current, and $i_{L}$ is the current superposition of the inductance $L_{1}$ and the inductance $L_{2}$.

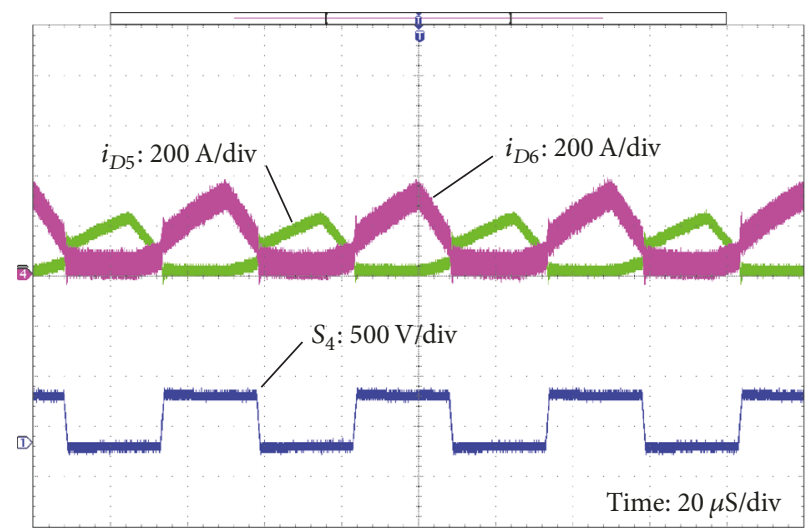

FIgURE 16: Two rectifier diodes: $i_{D 5}$ and $i_{D 6}$. The lagging-leg switching voltage: $U_{S 4}$.

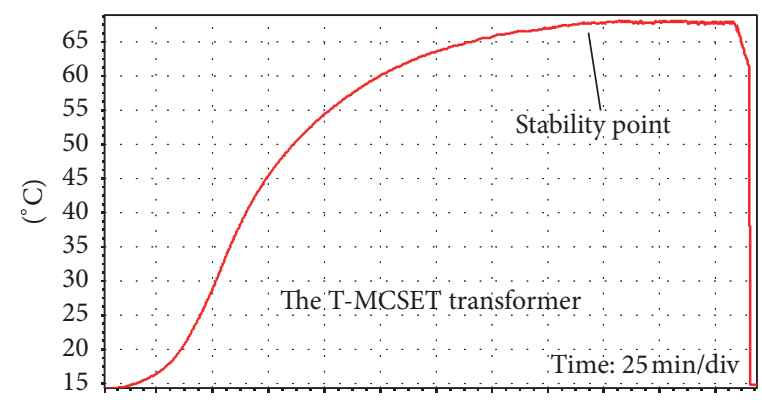

(a)

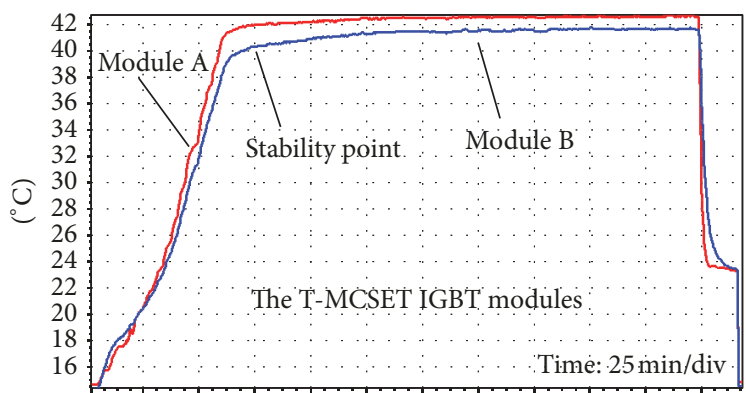

(c)

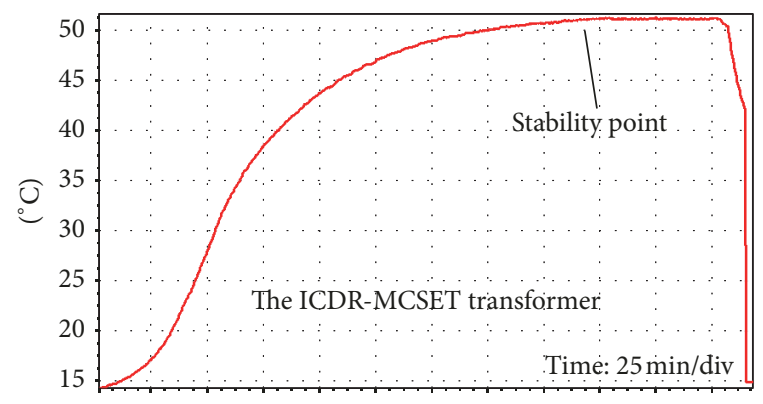

(b)

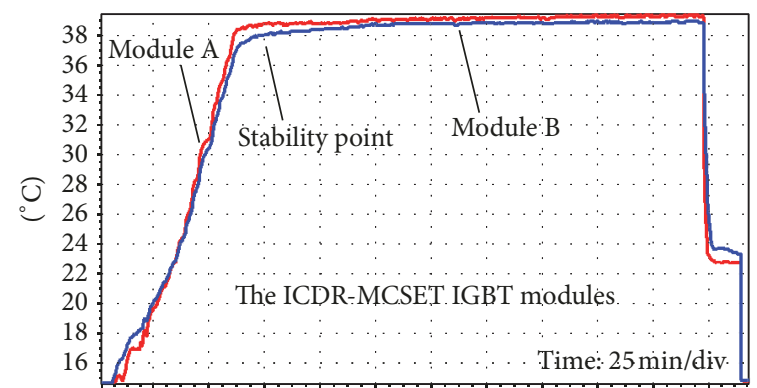

(d)

FIGURE 17: Temperature curve of the MCSET key components. 


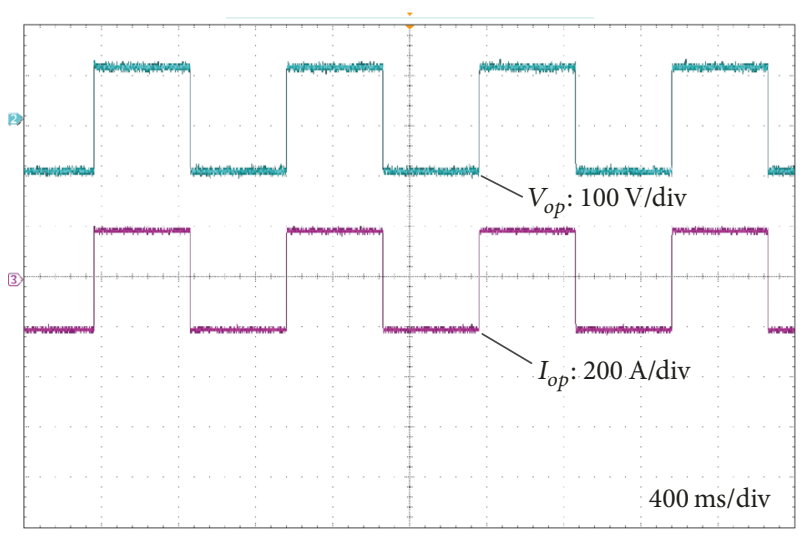

FIGURE 18: The transmitter emitting the voltage waveform $V_{o p}$ and the current waveform $I_{o p}$.

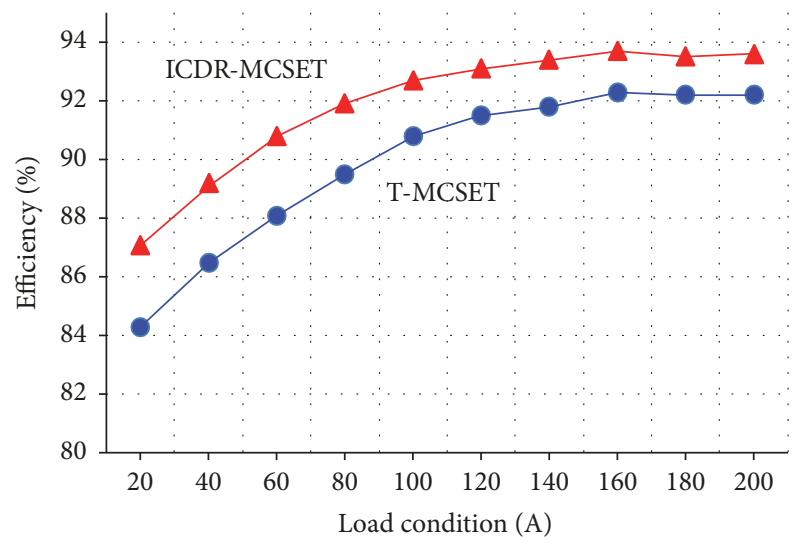

FIGURE 19: The contrast curve diagram of the efficiency and the load current.

second buffer in the process of rising; the lagging-leg switching successfully achieves soft switching; and the temperature, conduction loss, heating capacity, and damage rate of the transformer and the IGBT modules are all reduced, extending their service life and improving the conversion efficiency of the controlled source circuit. The results show that the temperature of the ICDR-MCSET transformer and IGBT modules is lower than that of the T-MCSET.

Good device cooling and extending the service life of the transformer and IGBT modules are an important issue in the design of the ICDR-MCSET; the heat of the transformer and IGBT modules is too high, and this will lead to changes in these devices' operating curve; excessive temperatures can cause damage to these devices.

As is seen in Figure 18, the marine controlled source transmitter emits a current and a voltage waveform of $1 \mathrm{~Hz}$ at the sea floor. This waveform exhibits a strong stability, good linearity, and high controllability. This substantiates the feasibility of the ICDR-MCSET.

As the load current increases, the conversion efficiency of the ICDR-MCSET rises (Figure 19). The maximum efficiency is $93 \%$ better than the T-MCSET. The experimental results demonstrate that the temperature of the IGBT tube decreases, the heat loss is reduced, and the efficiency of the DC-DC converter is improved in ZVS mode.

\section{Conclusion}

(1) This paper proposes an improved current-doubler rectifier for the marine controlled source electromagnetic transmitter (ICDR-MCSET). The blocking capacitor is added and the resonant inductance is increased within the MCSET. The zero-voltage switching condition of the IGBT tube is analyzed, the expression of achieving the zero-voltage switching is given, and the corresponding formula is deduced. The appropriate saturated inductance is chosen to obtain high conversion efficiency. Finally, the lagging-leg switch $U_{S 4}$ successfully achieves soft switching from the waveforms of the Saber simulation and the ICDRMCSET. This shows that this method is feasible and effective.

(2) Under the same condition, the temperature recorder is effectively used to record the temperatures of the transformer and IGBT modules in the laboratory. The results show that the temperature of the ICDRMCSET transformer and IGBT modules is lower than that of the T-MCSET. The efficiency of the ICDRMCSET is improved by about $1-3 \%$ under the entire load condition when compared to the T-MCSET, so conduction loss, heating capacity, and damage rate of the transformer and IGBT modules are all reduced, extending their service life, and the efficiency of the ICDR-MCSET is further improved.

(3) Due to the small and hermetic space of the underwater pressure cabin, the emission power of the ICDRMCSET is relatively large and is $20 \mathrm{KW}$; besides, the ICDR-MCSET needs to run for a long time; the heat dissipation and layout requirements of the devices are relatively high in the underwater pressure cabin to improve the power density of the ICDR-MCSET.

(4) The Saber simulation and the ICDR-MCSET are used in the laboratory to verify the conclusion. The experimental waveform and analysis are given, and the developed marine electromagnetic detection system draws on the latest technology of switching power supply, in order to obtain high stability, high linearity, high power density, and high transmission efficiency of the ICDR-MCSET. The stable emission current will take marine electromagnetic survey to a new level.

\section{Conflicts of Interest}

The authors confirm that this paper's content has no conflicts of interest.

\section{Acknowledgments}

This work was supported by the Strategic Pilot Science and Technology Program of the Chinese Academy of Sciences 
(B) (Research on Key Technologies of Controlled Source Marine Electromagnetic Launch Equipment in Deep Sea Bucket Area), Grant no. XDB06030204.

\section{References}

[1] J. He, "Principles of marine electromagnetic method," in Higher Education Press, pp.1-6, 2012.

[2] M. C. Sinha, P. D. Patel, M. J. Unsworth, T. R. E. Owen, and M. R. G. Maccormack, "An active source electromagnetic sounding system for marine use," Marine Geophysical Research, vol. 12, no. 1-2, pp. 59-68, 1990.

[3] S. Constable, "Ten years of marine CSEM for hydrocarbon exploration," Geophysics, vol. 75, no. 5, pp. X75-A81, 2010.

[4] K. Mehta, M. Nabighian, and Y. Li, "Controlled source electromagnetic (CSEM) technique for detection and delineation of hydrocarbon reservoirs: an evaluation," in Proceedings of the SEG Technical Program Expanded Abstracts 2005, pp. 546-549.

[5] S. Petersen, M. Hannington, T. Monecke, and G. Cherkashov, "Are modern seafloor massive sulfide deposits a possible resource for mankind: Lessons learned from shallow drilling operations," in Proceedings of the MTS/IEEE Kona Conference, OCEANS'11, usa, September 2011.

[6] D. Myer, S. Constable, and K. Key, "Broad-band waveforms and robust processing for marine CSEM surveys," Geophysical Journal International, vol. 184, no. 2, pp. 689-698, 2011.

[7] A. Orange, K. Key, and S. Constable, "The feasibility of reservoir monitoring using time-lapse marine CSEM," Geophysics, vol. 74, no. 2, pp. F21-F29, 2009.

[8] G. Schultz, J. Miller, F. Shubitidze, and R. Evans, "Underwater controlled source electromagnetic sensing: Locating and characterizing compact seabed targets," in Proceedings of the OCEANS 2012 MTS/IEEE Hampton Roads Conference: Harnessing the Power of the Ocean, USA, October 2012.

[9] S. Constable and L. J. Srnka, "An introduction to marine controlled-source electromagnetic methods for hydrocarbon exploration," Geophysics, vol. 72, no. 2, pp. WA3-WA12, 2007.

[10] N. H. Kutkut, D. M. Divan, and R. W. Gascoigne, "Improved full-bridge zero-voltage switching PWM converter using a twoinductor rectifier," IEEE Transactions on Industry Applications, vol. 31, no. 1, pp. 119-126, 1995.

[11] J.-M. Wang, S.-T. Wu, S.-C. Yen, and H.-J. Chiu, "A simple inverter for arc-welding machines with current doubler rectifier," IEEE Transactions on Industrial Electronics, vol. 58, no. 11, pp. 5278-5281, 2011.

[12] H. Tao, Y. Zhang, and X. Ren, "Small-Signal Modeling of Marine Electromagnetic Detection Transmitter ControlledSource Circuit," Mathematical Problems in Engineering, vol. 2015, Article ID 754379, 2015.

[13] R. Redl, N. O. Sokal, and L. Balogh, "A Novel Soft-Switching Full-Bridge DC/DC Converter: Analysis, Design Considerations, and Experimental Results at $1.5 \mathrm{~kW}, 100 \mathrm{kHz}$," IEEE Transactions on Power Electronics, vol. 6, no. 3, pp. 408-418, 1991.

[14] R. Redl, L. Balogh, and D. W. Edwards, "Optimum ZVS full-bridge DC/DC converter with PWM phase-shift control analysis design considerations, and the experimental results," in Proceedings of the 9th Annual Applied Power Electronics Conference and Exposition. Part 1 (of 2), pp. 159-165, February 1994.
[15] H. Tao, Y. Zhang, and X. Ren, "A Novel Circuit of Marine Controlled-source Electromagnetic Transmitter," Electric Power Components and Systems, vol. 44, no. 9, pp. 1063-1070, 2016.

[16] F. Yu and Y. Zhang, "Modeling and control method for highpower electromagnetic transmitter power supplies," Journal of Power Electronics, vol. 13, no. 4, pp. 679-691, 2013.

[17] B. L. C. Martinez, R. Li, K. Ma, and D. Xu, "Hard switching and soft switching inverters efficiency evaluation," in Proceedings of the 11th International Conference on Electrical Machines and Systems, ICEMS 2008, pp. 1752-1757, chn, October 2008.

[18] J. Kedarisetti and P. Mutschler, "Efficiency comparison between motor friendly hard and soft switching inverters," in Proceedings of the 2011 14th European Conference on Power Electronics and Applications, EPE 2011, gbr, September 2011.

[19] X. Ruan, J. Wang, and Q. Chen, "An improved CurrentDoubler-Rectifier ZVS PWM full-bridge converter," in Proceedings of the 2001 IEEE 32nd Annual Power Electronics Specialists Conference, pp. 1749-1754, Canada, June 2001.

[20] T.-F. Wu, C.-T. Tsai, Y.-D. Chang, and Y.-M. Chen, "Analysis and implementation of an improved current-doubler rectifier with coupled inductors," IEEE Transactions on Power Electronics, vol. 23, no. 6, pp. 2681-2693, 2008.

[21] H. Qin, Z. Yang, Z. Ren, H. Wang, "Comparison of Several Secondary Rectification Topologies in Isolated Low-voltage Highcurrent Output DC/DC Converter, Power Supply Technologies and Applications," vol,12, pp. 607-614, 2001.

[22] H. Chen, X. Wu, C. Hu, M. Chen, and F. Z. Peng, "A hybrid ZVS full-bridge converter with transformer winding series-parallel auto regulated current doubler rectifier," in Proceedings of the 4th Annual IEEE Energy Conversion Congress and Exposition, ECCE 2012, pp. 2209-2214, USA, September 2012.

[23] X. Ruan and J. Wang, "Calculation of the resonant capacitor of the improved current-doubler-rectifier ZVS PWM full-bridge converter," IEEE Transactions on Industrial Electronics, vol. 51, no. 2, pp. 518-520, 2004.

[24] W.-J. Lee, C.-E. Kim, G.-W. Moon, and S.-K. Han, "A new phase-shifted full-bridge converter with voltage-doubler-type rectifier for high-efficiency PDP sustaining power module," IEEE Transactions on Industrial Electronics, vol. 55, no. 6, pp. 2450-2458, 2008.

[25] J. Zhang, F. Zhang, X. Xie, D. Jiao, and Z. Qian, "A novel ZVS DC/DC converter for high power applications," IEEE Transactions on Power Electronics, vol. 19, no. 2, pp. 420-429, 2004. 


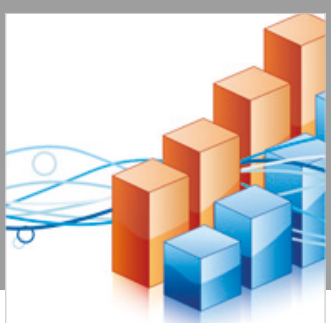

Advances in

Operations Research

\section{-n-m}
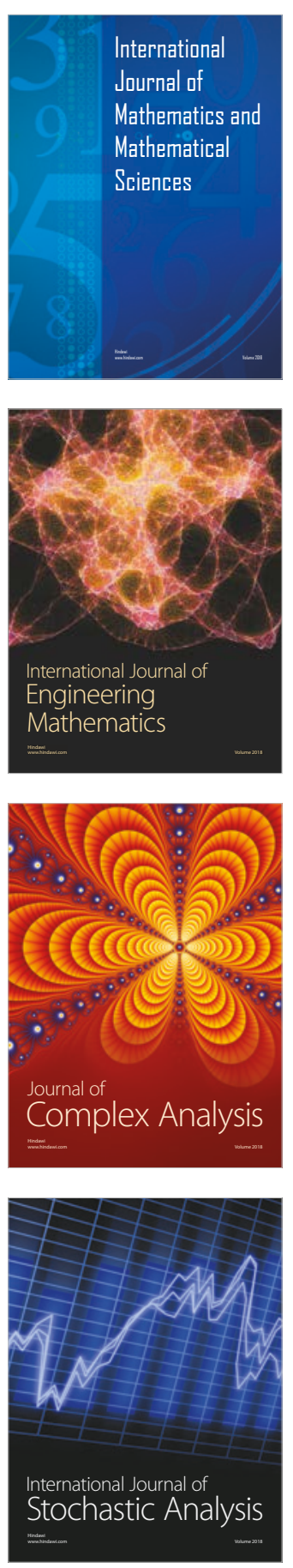
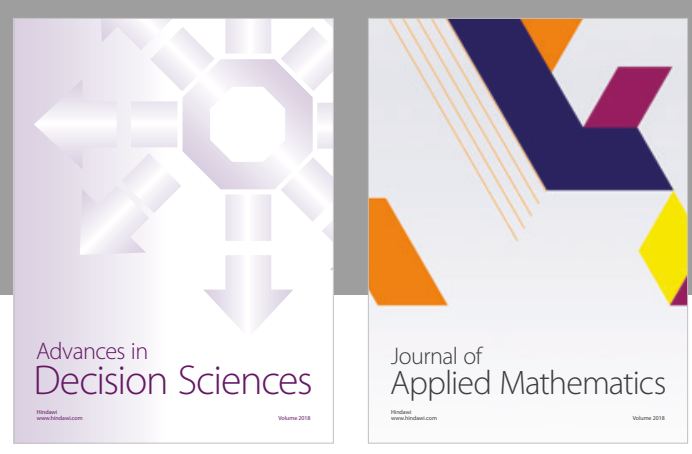

Journal of

Applied Mathematics
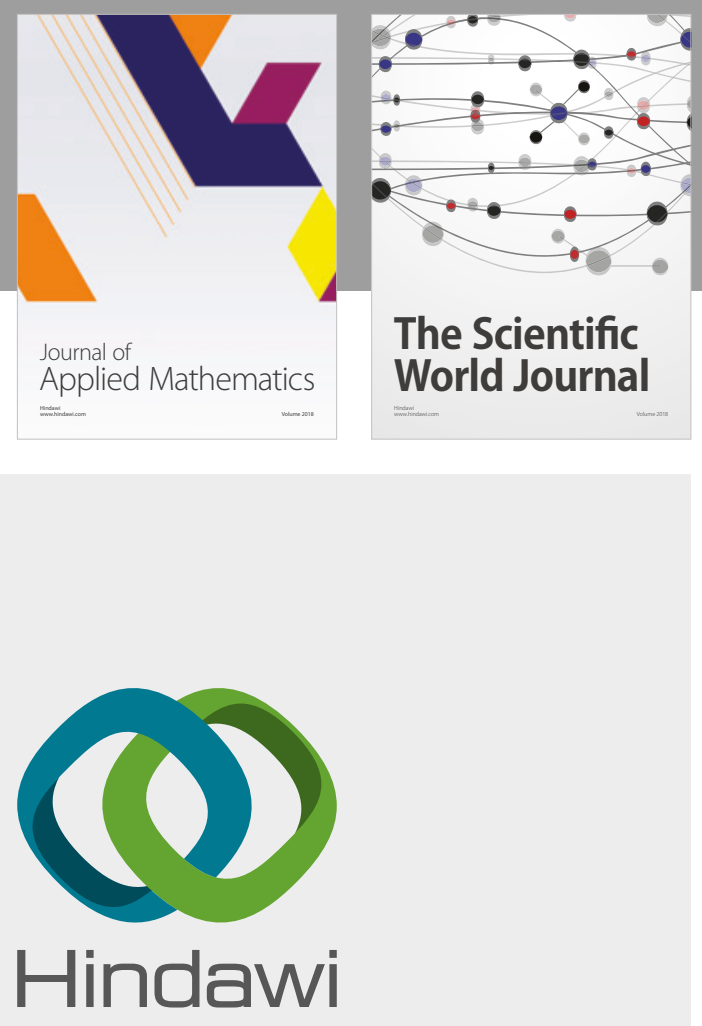

Submit your manuscripts at

www.hindawi.com

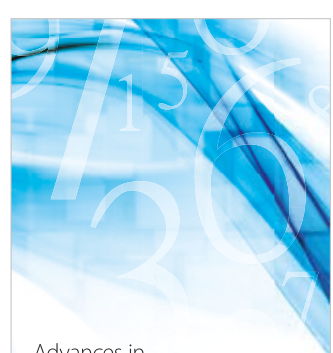

Advances in
Numerical Analysis
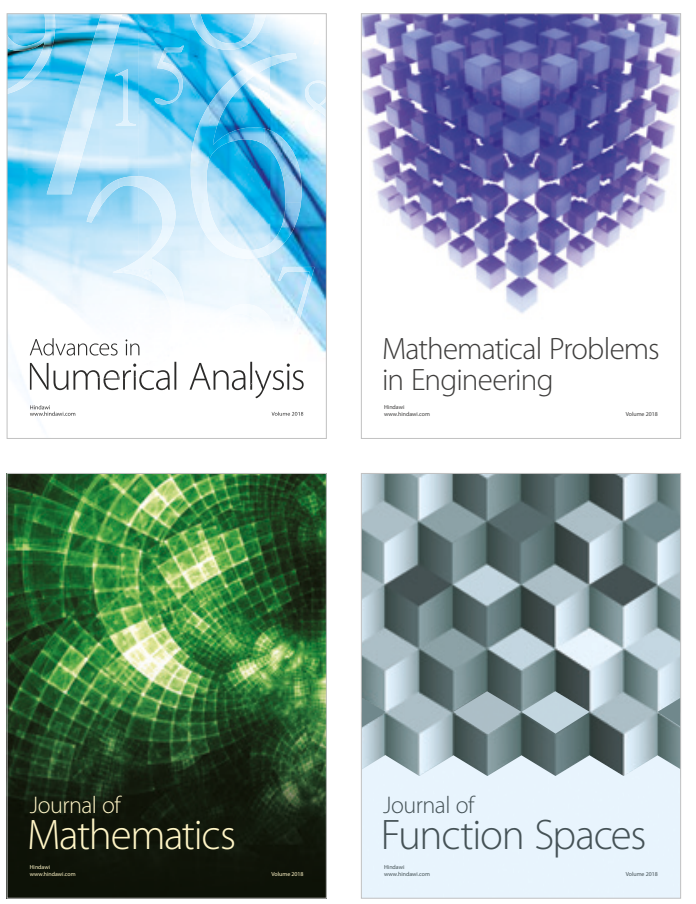

Mathematical Problems in Engineering

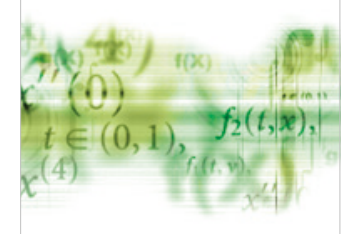

International Journal of

Differential Equations

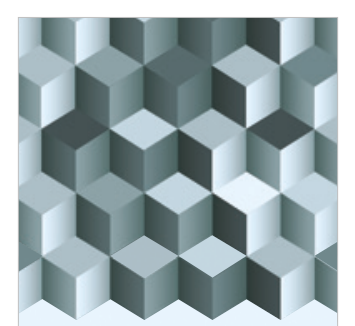

Journal of

Function Spaces

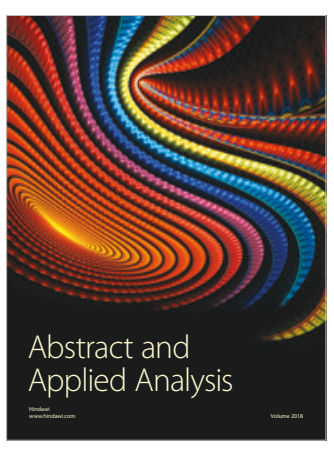

The Scientific

World Journal

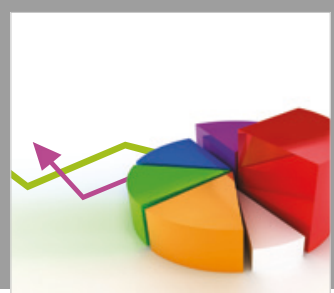

Journal of

Probability and Statistics
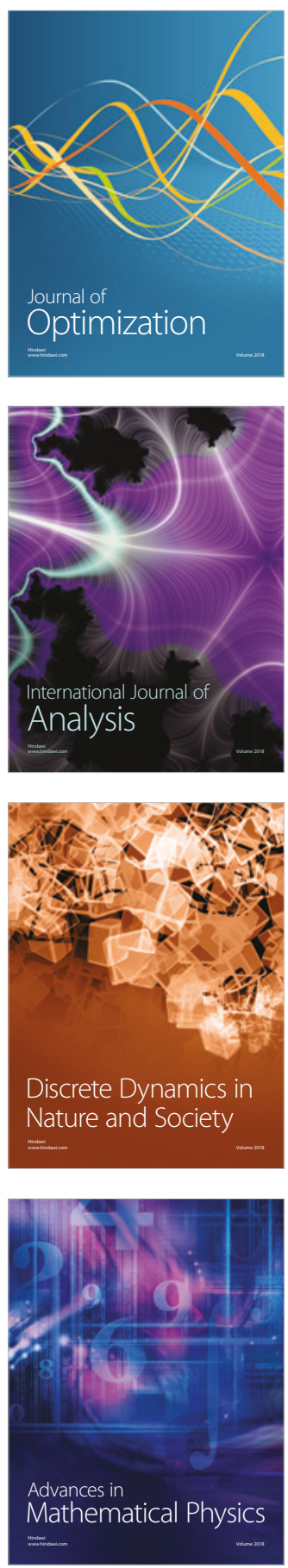